\title{
NOTAS PARA UN POSIBLE ESTUDIO DE LAS RELACIONES ENTRE ALFONSO REYES Y LOS CONTEMPORÁNEOS. EL CASO DE DON ALFONSO Y NOVO ${ }^{1}$
}

Lo que sigue, tomado de la fuente original, esto es, de una sección de anécdotas de escritores que publicaba la revista Antena de Francisco Monterde, allá por el año de 1924, lo contó Xavier Villaurrutia:

No era, claro, un viaje fantástico nuestro viaje. Tampoco pecaba de uniformidad y costumbre. Íbamos a Puebla, Salvador Novo y yo. En el tren, cuando no estábamos mudos de paisaje, cuando Salvador Novo no tomaba apuntes para su poema cartesiano, charlábamos con Valle, o con Zavala, o con el italiano viajero. Desde antes de entonces, Salvador, disciplinado, ureñizado a pesar suyo, acentuaba, señalaba y corregía las erratas verbales de los conversadores. Con su estatura -imaginad-, había crecido un repetido afán de enmendarlo todo. Así, gran parte del viaje.

Apenas llegados a Puebla, Zavala y yo emprendimos la fuga para librarnos de la seguridad despaciosa de Novo. Pero ;ay! en el cuarto del hotel, cuando abríamos el sobre de nuestra ropa de cama para que, entrados en él, el sueño nos llevara francos de porte a cualquier sitio, irrumpió Salvador Novo, ávido más que siempre de agua de corrección. Claro que, al poco rato, nuestra zozobra nos dictó la medida de un sueño fingido. Salió entonces Salvador Novo vibrante de insomnio, buscando algo que enmendar. Puebla toda se escondía en su casa de sombra, y la catedral no ofrecía erratas notables. . . Novo, decidido, tuvo que presentarse a La Opinión, el único

${ }^{1}$ Sobre las relaciones entre el grupo de Contemporáneos y Alfonso Reyes, en particular sobre el fenómeno del nacionalismo y los escritores mexicanos que de manera tan aguda se hizo presente de los años veinte de este siglo en adelante, véase "México, Alfonso Reyes y los Contemporáneos", recopilación de cartas y textos diversos, preparada por mí y publicada en $R U M e x$, 1967, núm. 9. Queda recogida aquí la polémica entre Reyes y Héctor Pérez Martínez que dio lugar al opúsculo $A$ vuelta de correo, de don Alfonso. 
diario de la ciudad, y con voz trémula rogó al redactor que preparaba la edición matinal:

${ }_{-}$QQuiere usted dejarme corregir las pruebas? ${ }^{2}$

Muchos años después (1960), en aquella sección muy sabrosa de leer, marcada por un estilo impar y que hoy resulta inestimable por la enormidad de datos y observaciones atesorados también, esto es, en "Cartas a un Amigo", heredera de "Cartas vie:jas y nuevas", de "La Semana Pasada", de "Side-Car", del "Diario de Salvador Novo" y de algunas otras secciones predecesoras en el tiempo que situaron a su autor como maestro y ejemplo de periodistas y escritores, apuntó el Cronista por antonomasia, así como al descuido, a la hora de ir pasando revista a libros recibidos por él:

Cuando uno tiene la costumbre de leer en diagonal, pronto encuentra lo que busca. Yo tengo ojo de corrector de pruebas y encuentro además las erratas, y las saco al margen con el lápiz (cursivas nuestras).

Sirvan estas referencias a fin de situar en primera instancia, vale decir, destacar la capacidad tipográfica - para decirlo de una vez- que Novo poseía de manera sobresaliente, lo que le permitió acometer una recensión de las Cuestiones gongorinas de don Alfonso, basada - casi- exclusivamente en este tipo de elementos; de esta suerte, con agudeza y especial - doble- envío le dedicó a un libro asaz erudito, preparado a su vez por un autor - Reyes, claro está- para quien una simple errata era motivo suficiente para provocarle malestares capaces de tenderlo en cama, la clase de nota que tal libro y tal preparador merecían de acuerdo a las intenciones, muy especiales por lo demás, del reseñista.

Seguidamente va la transcripción de dicha nota, la cual, cabe destacar, ha sido pasada por alto, cuando no ignorada, por reyistas y contemporaneólogos.

\section{EL CORRECTOR DE PRUEBAS CUESTIONES GONGORINAS DE ALFONSO REYES}

SALVADOR NOVO

Página 15.-Última línea de la nota (1), agregar: (página 144). Página 16.-Nota (1), línea 2 agregar: (página 30). p. 57.

2 Xavier Villaurrutia, "Novo, corrector", Antena, 1924, núm. 111, 
Página 17.-Nota (1), línea 1, Todas las (debe ir en cursiva).

Página 18.-Línea 18, latranscribe, la transcribe.

Página 30.-Línea 5, amenas, almenas.

Página 46.-Nota (1), línea 2, edción, edición.

Página 59.-Línea 7, llamar (') (Véase adelante, página 174, nota).

Página 62.-Nota (1), línea 2, agregar: (páginas 77 y 79).

Página 68.-Nota (1), intercalar en Rivadeneyra XXXII'’), página 491 a, nota 49).

Página 70.-Línea 9, intercalar antes del punto: (Véase adelante página 251, línea 19).

Página 73.-Línea 5 agregar: (Véase atrás página 11), línea 21, agregar: (XXXII 418 a). Nota (1), línea 2, agregar: (página 262).

Página 74.-Llamar ('): (Véase adelante página 149). Nota (1), línea 7, agregar: (Véase página 133 y particularmente páginas 152 y siguientes).

Página 75.-Nota (1), agregar: (Véase página 83). Nota (2), agregar: (Véanse páginas 85 y 87 ).

Página 79.-Nota (1) línea 2, añadir: (página 14); línea 4, añadir: (página 247 y siguientes. Véase especialmente página 252 ).

Página 82.-Línea 2, aclarar: (página 595 b) y agregar: (Véase adelante páginas 84 línea 24 , y 85 línea 3 ).

Página 84.-Línea 24, aclarar: (Véase atrás página 82, línea 2, y al frente, línea 3).

Página 85.-Línea 3, agregar: (Rivadeneyra XLII, página 595 a y b).

Página 89.-Nota (1), línea 3, añadir: (Véase página 133).

Página 98.-Línea 3, quanto si, quanto al? el?

Página 99.-Nota (1), línea 2, añadir: (páginas 11 y siguientes).

Página 102.-Línea 8, agregar: (soneto CXLVII, página 144a).

Página 111.-Nota (1), línea 3, agregar: (página 113).

Página I16.-Línea 12, da'berlles, d'abeilles.

Página 119.-Línea 26, queren, quieren.

Página 121.-Línea 10, aclarar: (página 490 c,) línea 11, aclarar: (página 93 a,) línea 18, añadir: "lo dice Janer en nota (1) al pie de la página 93 a del tomo 69 de Rivadeneyra, como comunicación de Barbieri"'.

Página 123.-Línea 14, añadir: (página 109).

Página 136.-Nota (1), línea 2, susrelaciones, sus relaciones. Nota (2) añadir: "particularmente página 109 y siguientes)". Nota (3) añadir: "Sobre la estética de Góngora" página 89 y "Sobre el procedimiento ideológico de Stéphane Mallarmé”, página 141).

Página 138.-Línea 4, quees, que es.

Página 141.-Nota (1), línea 11, añadir: (Véase página 37).

Página 144.-Nota (1) añadir: (página 15).

Página 149.-Nota (2) aclarar: (Páginas 37 y siguientes. Principalmente página 74.) 
Página 152.-Línea 3, agregar: (543b), añadir: (Página 74), línea 11, aclarar, (página 547 a), línea 19 aclarar: (página 544 c).

Página 154.-Línea 3, aclarar: 418 a.

Página 157.-Línea 16, aclarar: página 543 b.

Página 158.-Línea 4, añadir: (página 156).

Página 161.-Línea 11, aclarar: 102 a, línea 17, aclarar: 158 a.

Página 162.-Línea 9, citar: (página 83), línea 14, aclarar: página 595 a.

Página 169.-Línea 15, meons, menos.

Página 171.-Línea 10, intercalar: (página 15, nota de la página 14, línea 11); línea 24 , tobe, to be.

Página 172.-Nota (1) línea 4, añadir: (página 90).

Página 174.-Nota (1) añadir: (Véase atrás, página 59, línea 7).

Página 184.-Nota (1). Se transcribe el mismo párrafo de las Súmulas del padre Juan Rodríguez (hoja 40), que 5 páginas adelante [189, nota (1) ], ha de darse como nota curiosa, un poco más amplia, pero la misma las dos veces. Además, en la nota de la página 184 se da a las Súmulas (línea 2) la fecha de 1641 y la de 1640 en la nota de la página 189 (línea 6).

Página 186.-Nota, línea 9, añadir: (página 191).

Página 189.-Nota (1) añadir: (Véase atrás, página 184, nota).

Página 193.-Nota (1), línea 11, tamben, también.

Página 206.-Línea 5, ect., etc.

Página 211.-Línea 25, venr, venir.

Página 223.-Línea 9, constió, consintió.

Página 234.-Línea 11, relacionar: (Véase atrás, página 70, líneas 11 y 14, y adelante, página 251 , líneas 17 y 19).

Página 251.-Línea 17, añadir: (Véase página 70, línea 11), línea 19: (Véase página 70, línea 14, y también página 243, líneas 11 y 14).

Página 252.-Línea 6, llamar: (') (Véase atrás, página 79 y nota al pie).

Página 253.-Línea 21, citar: (página 250, línea 2).

Página 254.-Línea 4, ichaud, Michaud.

Página 256.-Nota (1) agregar citando: "he declarado, y me lo han creído, que soy el Secretario perpetuo del Góngora Club".

Página 263.-Línea 24, agregar: (páginas 105 y 106). ${ }^{3}$

Como se desprende de una atenta lectura, es muy posible que esta nota despojada de galanuras críticas de otra especie (pero preñada de elocuencia en su mensaje, ése en el que otro, de no ser don Alfonso - y Xavier Villaurrutia, que estaba en el secreto, como se verá después-, percibiría apenas una boutade en el mero listado de achaques de imprenta), así como aquella otra crítica que Dámaso Alonso dedicó al libro en la Revísta de Filología

${ }^{3}$ Publicado en Ulises, 1927, núm. 4, 39-40. 
Española ${ }^{4}$, hayan sido las que mayor atención habían inducido en quien, como lo señaló Villaurrutia en comentario que escribió a edad muy temprana todavía, había sido acogido en la Revue Hispanique por el "severísimo Foulché-Delbosc"5.

No obstante, broma y pulla son una realidad que se halla de manera omnipresente y harto directa en el ánimo de recensión tan peculiar de Novo; no obstante, asimismo, que su obsesión correctora fue constante en él hasta los últimos años de su vida, es más profundo lo que subyace en ese pícaro y risueño afán de estremecer a don Alfonso pasándole enfrente no un fantasma únicamente, sino una ristra de ellos enfundados en la sábana de la errata. Ello viene a ser pecado imperdonable en este caso, máxime cuando la edición de que surgen todos eșos trasgos supuestamente debía estar cuidada con un empeño de microcirujano.

$\mathrm{Y}$ va de historia, en fin, tal como me fue narrado por el propio ejecutor, el antecedente de ese enfoque bibliográfico que figura indiscutiblemente como uno de los más originales dentro de la trayectoria de la crítica en México; asunto que, por otra parte, ilumina con fuerza tanto el aspecto medular de la relación personal Reyes-Novo como aquel otro que corresponde al marco generacional en el que se inscriben figura y obra del autor de la Nueva grandeza mexicana.

Ulises, la revista de Novo y Villaurrutia, sueño de ambos hecho posible gracias a la generosidad y al espíritu irrepetible de Antonieta Rivas Mercado, fue en cierta medida lo que no fueron (aun cuando haya habido alguna pretensión de ello) ni la precedente La Falange, ni la posterior Contemporáneos (las más importantes de las publicaciones hechas por la totalidad del "grupo sin grupo"), es decir, una especie de "Correo literario" a la manera en que lo concibió y practicó Alfonso Reyes en su Monterrey en versión individual.

Aun cuando Novo afirmó en 1966, en la carta con que hace preceder la edición de las que Villaurrutia le dirigió de Yale a México, que "desde la barca de Ulises [la revista] te comunicaste con un Alfonso Reyes tan consonante a la distancia contigo", ${ }^{6}$ lo cier-

${ }^{4}$ Dámaso Alonso, reseña de Cuestiones gongorinas, de A. REYES, RFE, 14 (1927), 448-454.

5 Xavier Villaurrutia, "Escritores mexicanos contemporáneos. Lic. D. Alfonso Reyes", Biblos, 1920, núm. 56, p. 22.

6 SAlvador Novo, "Carta-prólogo" a Cartas de Villaurrutia a Novo, INBA, México, 1966. 
to es que el acercamiento entre don Alfonso y Villaurrutia se dio, no en 1927 como apunta Novo, sino en 1923, a raíz de un comentario crítico que Xavier escribió sobre el poemario Huellas de Reyes en las páginas de la revista La Falange ${ }^{7}$.

De allí arrancaría la relación sólida y productiva en la que Novo también fijaría sus amarras bien apretadas hasta la muerte de don Alfonso, y aun cuando menos próximo a éste en un principio que Villaurrutia, recibía su atención por conducto de Xavier.

Al llegar a este punto en que se hace referencia al inicio de un trato entre amigos - ¿o sería mejor decir entre maestro y discípulos? - resulta interesante acudir a un testimonio en cuyo contexto surge la circunstancia más que sugestiva de que el comienzo de la relación de esos dos Contemporáneos estuvo signado por los manes de Alfonso Reyes. Véase, en fin, lo que a este respecto apuntó Novo en un artículo en el que, muy joven todavía, pasaba ya revista al decurso de su existencia:

Corrieron veloces los años. Dos más tarde, en 1919, conocía yo a Xavier Villaurrutia. A short fellow, con pantalones cortos. Le interesó saber que yo hiciera versos. Él ya cursaba literatura con - ¿será necesario decirlo? - don Erasmo Castellanos Quinto. Y como vivía por el camino que yo hacía diariamente a la Preparatoria, pasaba yo por él en las tardes y nos íbamos conversando a clase. El sabía una enorme cantidad de cosas que yo ignoraba. Tenía unas Cuestiones estéticas de Alfonso Reyes, dedicadas a algún pariente suyo que no debe haber sido don Jesús Valenzuela, sin embargo. Më hizo leerlas y me habló de Antonio Castro Leal ${ }^{8}$.

Como queda anotado anteriormente, Villaurrutia escribió un comentario acerca de Huellas, lo que dio pie a que Reyes le enviase una carta - todavía sin que hubiera trato directo entre ellosen la que, de manera firme aun cuando planteada con donaire su reclamación, manifestaba su inconformidad por no ser considerado por el comentarista de su libro, ya no un buen poetá, sino simplemente poeta. La respuesta epistolar de Villaurrutia sentó las bases de un intercambio que sólo su muerte interrumpiría ${ }^{9}$.

7 X. Villaurrutia, reseña de Huellas de A. Reyes, en La Falange, julio de 1923, 248-249.

${ }^{8}$ Salvador Novo, "Veinte años después", Revista de Revistas, 1929, núm. 1000 , p. 44.

9 JACQUES IsSOREL, "Seize lettres inédites de Xavier Villaurrutia à Alfonso Reyes", Carav, 1974, núm. 23, 47-61. La carta inicial enviada por Reyes a Villaurrutia no aparece en esta publicación; fue localizada por mí después de 
A lo largo de ese diálogo se dio, además de la comunicación estrecha, la prolongación de la atención crítica de X.V. a la obra de Reyes y los buenos oficios de éste para que Nostalgia de la muerte de Villaurrutia se publicara en Buenos Aires con el sello editorial de Sur, entre otras cosas. El acercamiento personal entre ambos se produjo cuando volvió don Alfonso a México en 1924, después de años de ausencia, y se continuó al asentarse el regiomontano en el país para dirigir La Casa de España en México (con cuyo pie editorial, igualmente, apareció Textos y pretextos en 1940), que a su tiempo sería El Colegio de México.

La actitud de Villaurrutia durante todo ese prolongado lapso (1923-1950) fue invariablemente la de quien sabe ejercer el juego de la inteligencia a su más alto nivel con un interlocutor de gran jerarquía intelectual igualmente, interlocutor que era al mismo tiempo para él no sólo el maestro, sino el dios tutelar, el consejero y el amigo.

Todas las manifestaciones de ello, expresadas dentro de los cánones del respeto máximo a una figura suprema y dentro asimismo de los cánones de una seriedad más propia del templo y de la cátedra que de la vida ordinaria. La mejor evidencia de esto son las cartas de Xavier a Reyes, las que contrastan notablemente con las que escribió a Novo desde Yale y en las que sí hay rasgos de humor y de una existencia más de acuerdo con impulsos vitales o cotidianos, valga la perogrullada.

Si he traído a cuento este asunto del carácter de Villaurrutia, así como la sucinta referencia a su relación con don Alfonso, es

que vio la luz el trabajo de Issorel. Será incluida en la edición del Epistolario. de los Contemporáneos que he preparado para el FCE. Acerca de este punto resulta bastante ilustrativo lo que aporta GUILLERMo SHERIDAN en Los contemporáneos ayer, FCE, México, 1985, pp. 144-146, aun cuando supone Sheridan que fue Villaurrutia quien se dirigió primeramente a Reyes. No obstante la excelente relación que se dio entre don Alfonso y Villaurrutia, y por más que -aparentemente - el mal sabor de boca que le dejara la nota de Villaurrutia había quedado diluido, no deja de ser significativa la siguiente acotación de don Alfonso: "Conservo críticas y crónicas encomiásticas [sobre Huellas] de Manuel Horta en El Heraldo de México (28 de enero de 1923), de·El Universal (México, 31 de enero), artículo sin duda debido a la fiel amistad de Carlos González Peña; de Julio A. Muñiz en El Heraldo de la Raza (México, 15 de febrero), de Norberto Pinilla en El Mercurio (Santiago de Chile, 3 de marzo), de.E. Suárez Calimano en Nosotros (Buenos Aires, diciembre), de F. Contreras en el Mercure de France (15 de abril de 1924); una nota algo reticente de Xavier. Villaurrutia, en La Falange, de México..." ("Historia documental de mis libros. XIII. El año de 1922. Continuación", $U M x, 1957$, núm. 1, p. 16; las cursivas son mías.) 
para destacar con mayor nitidez las aristas del temperamento absolutamente opuesto que definía a Salvador Novo, ya que el modo de ser desenfadado y chocarrero con el que siempre se desenvolvió en la vida, en las letras y en el periodismo, ocasionó que más de una vez no se le considerase apto para la literatura en un país donde para ejercerla y por las muestras que de ella había hasta los años veinte de este siglo, parecía que el ingrediente básico para ser considerado escritor era la solemnidad y, por lo tanto, el humorismo era motivo de reprobación pues equivalía a algo no sólo molesto para el carácter nacional sino una cosa semejante al ripio.

Su espíritu más libre, pues, que el de Villaurrutia, juguetón, imbuido de gracia, de un humorismo sin restricciones, de una ironía diestramente manejada, elementos todos estos que prácticamente aclimató en mitad de un país hierático, archisolemne, le daba una imagen de poca seriedad ante los representantes de una república de las letras, adustos y tiesos "como buenos ídolos aztecas" - son palabras de Novo- que parecían ser a su lado los integrantes de la casi totalidad de la comunidad literaria local.

Lo desconcertante, sin embargo, no era tanto que escritores de mayor edad que él, o aquellos inmersos en otra manera de avenirse con la vida y la literatura, tuvieran una actitud que llegaba incluso al rechazo del jaez gracioso que se desprende de sus escritos, sino que aun el propio Villaurrutia, tan cercano y parecido a Novo en muchas otras cuestiones, disintiera de esta forma de enfocar la materia literaria (lo cual, por lo demás, bien mirado, no resulta del todo sorprendente, sino que enfatiza el carácter de un conjunto de escritores cuyo nombre, Contemporáneos, "aspiraba a vincular no más que en el tiempo de [su] coexistencia independiente, a un grupo tan celoso de su individualidad, que mostraba empeño especial en subrayarla"10.

Sobre este asunto del humor en las letras y la diferente visión que acerca de ello tenían estos amigos que - dentro de esa fraternidad que constituyeron en el marco más amplio de la literatura mexicana, fueron justamente de los más contiguos entre sí- existe un ejemplo que pone de relieve esa circunstancia y por medio del cual se ve aparecer también a don Alfonso en ese contexto.

Resulta que, como bien lo expuso Villaurrutia al comienzo de un texto dedicado también a examinar el alcance de la obra

${ }^{10}$ Salvador Novo, La vida en México en el periodo presidencial de Miguel Alemán, ed. José Emilio Pacheco, Empresas Editoriales, México, 1967, p. 362. 
de J. Joaquín Fernández de Lizardi en el panorama cultural de nuestro país:

De cuando en cuando soplan en México huracanes de nacionalismo. Se alaba desmesuradamente lo nuestro, se reduce lo nuestro a elementos decorativos. A veces, afortunadamente, también se estudia lo nuestro. Ayer fueron los jóvenes del Ateneo. Ahora somos nosotros, los jóvenes, ¿de dónde? Digamos del "grupo sin grupo""11.

Esta afirmación se encuentra en el artículo que, con el significativo título de "Mi Pensador Mexicano", escribió el autor para, en gran medida, dar respuesta al que Novo había publicado meses antes en las páginas de la misma revista bajo el encabezado meramente de "El Pensador Mexicano"12.

Texto este último animado con toda la gracia propia del jovencísimo autor; gracias a ese elemento, esto es, a la gracia, a la ligereza, se nos presenta al precursor de la novela hispanoamericana y de nuestro periodismo (y de quien Novo es justamente en este último aspecto, un excelente continuador en el tiempo, sobre todo en aquellas colaboraciones dialogadas que publicaba en su columna "Ventana" del diario Novedades), desde una perspectiva que hace entender al menos, si no justificar del todo, ese afán moralizante y reformador lizardiano que invade todas sus páginas, puesto que, como afirma el joven Salvador:

Yo hallo, en nombre de Freud, al maniático, para quien la vida está mal y cuya gloria estaría en alcanzarla en la tierra por medio de la buena conducta, del buen vivir católico y de las lecturas saludables de Horacio, a quien cuida de citar y trata de traducir muy frecuentemente, seducido por el utile dulci...

Sólo que Novo en su admiración, en su entusiasmo lizardistas - para nada compartidos por Villaurrutia-, expresa algunas afirmaciones que provocan que el segundo llegue incluso a una reprobación del modo en que su colega aborda las cuestiones literarias, especialmente las que tienen que ver con México; es así que, como puede verse por el fragmento transcrito a continuación, prác-

1 Xavier Villaurrutia, "Mi Pensador Mexicano", El Universal Ilustrado, 18 de septiembre de 1924; recopilado en Obras, $2^{\mathrm{a}}$ ed. aumentada, FCE, México, 1966, pp. 790-792.

12 Salvador Novo, "El Pensador Mexicano", El Universal Ilustrado, 24 de julio de 1924; recopilado en Ensayos, Talleres Gráficos de la Nación, México, 1925, pp. 62-65. 
ticamente arremete contra Novo cuando éste proyecta su atención sobre el "Pensador":

También Salvador Novo, con esa curiosidad insaciable que tanto le favorece y que tanto le difunde, se ha asomado al paisaje impresionista de nuestras letras iniciales, llegando a caer, insólito, hasta en los terrenos precortesianos. Tratando estos asuntos - Nezahualcóyotl, rey y poeta traducido del inglés-, me produce el mismo efecto que a los chichimecas les habría producido el aterrizaje de un avión en sus tiempos y en sus dominios. Hay algo de modernísimo en el "genio y figura"' de Salvador Novo que le impide aparecer natural en tales incursiones. Hablando de Fernández de Lizardi, acierta en su manera de justificarlo, humanizándolo. En cambio, se aprovecha para lanzar los dardos de su humorismo insinuando que "de haber vivido en estos tiempos sería el jefe de la campaña contra el analfabetismo"', sin recordar que, además de jefe, por momentos, Lizardi merecería formar parte de su propio ejército ${ }^{13}$.

Se pueden apreciar, en fin, los avatares de un humorista en un ambiente poco propicio al franco estallido de la carcajada - jvaya, pero ni siquiera al de la sonrisa! - y esto se revela con mayor claridad por la cita anterior de alguien que se supondría mayormente capaz de aprehender el sentido igualmente trascendental que radica en el humor.

Ahora bien, por lo que toca a la participación de don Alfonso en esta polémica entre cofrades - al fin y al cabo menor-, si bien no se realizó de una manera directa, no deja de tener su importancia, pues refleja el peso definitivo de una obra sobre muchas otras, en este caso sobre quienes iban en ascenso, como Novo y Villaurrutia.

Así, en su artículo, sin hacer referencia explícita a ello, Novo manifiesta claramente que conocía el texto que con el título " $E l$ Periquillo Sarniento y la crítica mexicana"' consagró Reyes a la obra de Lizardi y que recogió en la Tercera Serie de sus Simpatías y diferencias. Como se recordará, apunta allí don Alfonso, entre otras cosas, que:

La popularidad de Lizardi (como novelista, se entiende) es la popularidad de un nombre o, mejor dicho, de un seudónimo. El Pensador Mexicano se llamó su periódico; "El Pensador Mexicano"' acostumbraba él firmarse; mas la gente vulgar piensa que la posteridad le atribuyó el mote de "Pensador" porque lo era, e ignora que el

13 Xavier Villaurrutia, “Mi Pensador...", p. 790. 
seudónimo deriva de El Pensador, del español Clavijo (1762 en adelante) $)^{14}$.

En el escrito que se viene mencionando, Novo se refiere a este comentario de don Alfonso, lo cual es la primera alusión que a él se hace en la vastísima obra de Novo, aun cuando, como se advierte por la cita que se hace seguidamente del pasaje, está omitido el título del trabajo sobre Lizardi, y Reyes queda evocado por medio de ese ligero pellizco que es el calificativo adjudicado a él por quitarle al Pensador su título de tal:

El Pensador - ;oh, cruel Alfonso Reyes! - si no precisamente pensaba, sí quería; quería el bien de su pueblo, anhelaba para sus prójimos la cultura que a él le había sido imposible alcanzar y por ello estableció, con fracaso, una sociedad pública de lectura, y escribió, con éxito, El Periquillo Sarniento, La Quijotita y su prima, Don Catrín de la Fachenda, Las noches tristes y el día alegre y piezas teatrales ${ }^{15}$.

A propósito de esta misma cuestión, Villaurrutia señala que "su seudónimo acabó por convertirse, en los cerebros de quienes lo admiran sin conocerle, en su calificativo", con lo que hace patente también que ha acudido al mismo arsenal, es decir, al texto de don Alfonso; esto queda corroborado con mayor rotundidad cuando explica el porqué de su recorrido por territorios lizardianos:

Mi intromisión quiere ser, si más modesta, más severa. Examinando lo que hay en el platillo que reconoce valores y fija contornos, sólo quiero decidirme por este último, advirtiendo que, si mi actitud pesara un poco, ayudaría a inclinar la balanza del lado que han contribuido a llenar Reyes y Urbina ${ }^{16}$.

${ }^{14}$ Alfonso Reyes, Simpatías y diferencias. Tercera serie, AROC, t. 4, p. 171.

15 Salvador Novo, Ensayos, p. 64. Cabe advertir que en una breve pieza de teatro publicada por Novo (Divorcio. Drama ibseniano en cinco actos, El Universal Ilustrado, 1 de mayo de 1924, recogido en Ensayos, pp. 44-52), en una especie de introito u "obertura", exhibe toda una nómina de lo que por entonces constituía el demier cri de la dramaturgia - fuera de México, desde luego- y entre los nombres citados incluye el de "Jean Cocteau -el enredador de Alfonso Reyes - nunca semejante a sí mismo [que] ha representado con fonógrafos Les mariés de la Tour Eiffel', aludiendo al mencionar a don Alfonso - sin precisarlo- al texto de 1923 en que éste revisa algunos conceptos, sobre todo, la metaforización que hace Cocteau del enlazamiento cuando habla del amor en sus obras. Véase A. REYEs, "Cocteau, enredador", en $A$ lápiz, AROC, t. 8, pp. 227-229.

16 Xavier Villaurrutia, Obras, p. 790. 
En otra parte de su colaboración amplía un tanto las razones de la afirmación precedente:

Con motivo de El Periquillo, ha recibido los más opuestos calificativos. Beristáin, Pimentel, Terán, Ramírez, Prieto, González Obregón, con sus reparos o sus elogios desmedidos cuando no injustos, han contribuido a hacer de la figura de este precursor de nuestras letras una mancha difusa. Luis G. Urbina, con humano buen sentido, y Alfonso Reyes, con afilada percepción, han formulado con serenidad y justicia juicios que empiezan a aclarar y fijar los contornos de la obra de Lizardi ${ }^{17}$.

${ }^{17}$ Más que el humor esgrimido por Novo, fueron otros conceptos empleados por el autor lo que ocasionó que su texto apareciera como una osadía tremenda ante los ojos de Villaurrutia, puesto que su veneración por don Alfonso era, en esos tiempos en que tan reciente estaba el comienzo de su relación con él, llevada al extremo de que no podía permitir, ni en él ni en ningún otro, ; a disensión con los juicios alfonsinos; prueba de ello fue la reacción de Xavier ante lo publicado por Novo, en particular como se deja ver por este fragmento del cual ya se ha mostrado aquí lo que opinó acerca del humorismo. Así, decía Novo: "De vivir hoy, un ministro inteligente lo hubiera ya nombrado Director de la Campaña contra el Analfabetismo y sería redactor de Excélsior. Hace un siglo apenas se le concedió el sueldo de capitán retirado, en premio a sus dudables servicios en Cuautla, durante el sitio de Morelos, y se le hizo redactor de la Gazeta. Y el hecho de que existen, aún hoy, aquel departamento y este periódico, prueba que todavía necesitamos de algunos pensadores mexicanos que olviden las cuestiones estéticas y amen a su país en las minucias espirituales que lo constituyen por idiosincrasia y que, dejando a un lado la obreritis internacional y el iberoamericanismo apliquen la actualidad social y literaria extranjera a este su país y de él extraigan Lazarillos, Guzmanes de Alfarache, Quijotitas, Negros Sensibles, $o$, con la prerrogativa que les conceden cien años más de vida y mil facilidades más de estudio y de perspectiva pacífica y no aguijoneada por el hambre, Mónicas Lerbier o Jean Christophes". (Las cursivas son mías.) Pocos, si no es que ningún otro, han acometido una defensa tan decidida y objetiva de un autor que aún hoy no alcanza a ser reconocido en su verdadera dimensión, ni a ser entendido en cuanto a la sinceridad y profundidad de sus reclamaciones, de sus afanes educativos, que tenían el sentido, ni más ni menos, de pretender que pudiera el pueblo, a la larga, convertirse, por lo pronto, en lector. Pero, digresiones aparte, no hay que descuidar el hecho de que en ese fragmento, con una actitud desusada en México, Novo arremetía, por una parte, sin nombrarlo, pero sí identificándolo con el título de su primer, consagratorio libro, Cuestiones estéticas, contra Alfonso Reyes y, por otra, contra Vasconcelos, cuya doctrina iberoamericanista le había llevado incluso a imponer en las calles del antiguo "Primer cuadro" de la capital, la aún subsistente nomenclatura que ostenta los nombres de los países centro y sudamericanos y del Caribe. Un hecho verdaderamente sorprendente, puesto que un joven que comenzaba de hecho sus actividades literarias cometía el desacato de lanzarse contra dos de los dioses mayores del Olimpo local. 
Ya la referencia de los mismos autores que han enjuiciado a Lizardi descubre igualmente a Villaurrutia como abrevador en la fuente alfonsina, puesto que son estos enumerados por él los mismos sobre los cuales monta Reyes su estudio de los críticos mexicanos con relación al Pensador.

Pero llegue hasta aquí esta digresión cuyo propósito, como antes se dijo, tiene la finalidad de mejor ubicar a un Novo que iniciaba su despegue para alcanzar las alturas literarias y al que no se le otorgaba merced de escritor; todo lo más, se le concedía la menos consagradora patente de periodista.

$\mathrm{Si}$ a todo lo que se ha venido exponiendo con respecto a Novo se le suma el asunto, no muy bien visto tampoco, de que casi precozmente, podría afirmarse, se dio a ejecutar los menesteres que lo encumbraron económicamente - cosa insólita entre el gremio$y$, unido a esto, el reconocimiento que todo el tiempo se hizo de su manejo certero de un lenguaje satírico, siempre demoledor de quien recibía sus venablos, se puede concluir de aquí que no era extraño - como él mismo lo reconocería en las postrimerías de su vida - que, además de carente de seriedad, se le considerase tanto una especie de nuevo Aretino como un mercenario intentando sentar plaza de intelectual, amén de ser temido y odiado $y$, añadiría yo, secretamente envidiado.

A lo anterior adjúntesele el agregado que suponía, la, para esos tiempos - y aún para hoy, no obstante las evoluciones y liberalidades que supuestamente hay para "el amor que no osa decir su nombre" - , circunstancia insólita, turbadora, no de su homosexualidad per se, sino de la manera en que él la hacía ostensible en el México ultra male chauvinist de los años veinte, como calificaría algún radical muy à la page a la nación que empezaba a despuntar después de la Revolución.

Fue en parte por lo acotado hasta este momento por lo que a don Alfonso - si bien era un hombre bonachón, generoso, abierto y a quien el humor no le resultaba ajeno, sino que le era consustancial- ciertas actitudes de Novo de aquellos años en que prácticamente se iniciaba le provocaron cierta inquietud, en particular una manera punto menos que heterodoxa de asumir la literatura como ejercicio, por lo cual en algunas ocasiones le envió cariñosas, sutiles exhortaciones a que abrazara las letras con más hondura; en suma, no se le alcanzaban a defininir con la fuerza que él exigía para sí mismo los perfiles de escritor de Novo, si bien nunca dejó de admirar y advertir ese enorme talento -o ese algo que se le figuraba un don como también una dispendiosa facili- 
dad: el llenado rapidísimo y bien logrado de cuartillas.

En el epistolario de don Alfonso y Xavier Villaurrutia se puede encontrar una clara muestra de la preocupación de Reyes por Novo. En comunicación enviada por Xavier el 15 de abril de 1925, refiere lo siguiente:

Voy a decirle algo sobre su Entreacto que le interesará:

Con el cambio de Secretario de Educación se suspendieron las publicaciones emprendidas - Platón tuvo que hacerse a un lado para dejar pasar a Edmundo de Amicis y su corazón desastroso. De sus poesías se había formado una buena parte.

Fueron, sin embargo, fundidas, globalmente, como todo lo principiado en otro régimen. Como el acuerdo subsiste, basta hacer memoria al Doctor Puig. También es preciso conseguir de algún modo el papel, pues el acuerdo sólo se refiere a la impresión. Salvador Novo se ofrece a cuidar conmigo la edición. Novo es el amigo que queda en el departamento de Julio Torri ${ }^{18}$.

A ello respondió don Alfonso lo que sigue:

Gracias por su carta y por las informaciones sobre Entreacto. He decidido recoger el original. Le ruego que procure el envío. El deseo de publicar algo en México, durante mi permanencia allí me hizo cometer la ligereza de formar ese libro apresurado. La casualidad, gran maestra, me avisa a tiempo...

Gracias a Salvador Novo por su amable disposición. ¿Qué hace él? No me gustaba verlo tan atado al duro banco de la crónica. ¿Se habrá emancipado ya de eso? ¿Deja reposar un poco su vino? (cursivas mías) ${ }^{19}$.

No cuesta trabajo, entonces, entender que Novo buscara demostrar de modo fehaciente y rotundo a Alfonso Reyes, en tanto que era éste la figura definitiva, realmente moderna e internacional de nuestras letras, algo que para él era esencial, su vocación profunda de escritor y su conocimiento igualmente a profundidad de la literatura en sus más diversas manifestaciones, para hacer evidente con ello también que frecuentaba no sólo la expresada en lengua inglesa, como era común el comentario, ocasionado por la interpolación que realizaba de anglicismos en sus escritos - lo cual era un elemento más de desdoro en un medio que úni-

$18 \mathrm{~J}$. IssOREL, art. cit., p. 51

${ }^{19}$ Carta inédita de Alfonso Reyes a Xavier Villaurrutia, enviada de París el 14 de mayo de 1925: Incluida en el Epistolario de los Contemporáneos, de próxima publicación. 
camente consideraba de buen tono salpicar con galicismos las muestras de una producción literaria que, con las excepciones de siempre, era ejemplo de un tardío modernismo.

Don Alfonso, por otra parte, al igual que lo había hecho con títulos anteriores suyos y aun con los de otros autores extranjeros - españoles y sudamericanos sobre todo-, así como notas sobre él que aparecían fuera del país, enviaba todo esto a Villaurrutia con preferencia sobre otros amigos mexicanos, para que se conocieran en México, como fue el caso de "La Ifigenia de Alfonso Reyes", texto de Eduardo Gómez de Baquero aparecido originalmente en Madrid ( $E l S o l, 4$ de febrero de 1926) y que Xavier reprodujo en El Universal Ilustrado; así, cuando en 1927 vio la luz Cuestiones gongorinas, lo remitió obligadamente a Villaurrutia.

La ocasión fue ideal para que nombre y obra de Reyes fueran acogidos en las páginas de Ulises donde, cabe aclarar, no aparecieron colaboraciones de él (como tampoco de José Gorostiza ni de Bernardo Ortiz de Montellano) y era la coyuntura perfecta para que, a pesar de las figuradas y aun manifiestas demostraciones de frivolidad que de Novo dimanaban, se supiera que entre el para entonces autor apenas de un libro y la literatura, existían relaciones más íntimas y también más amplias que aquéllas que a los ojos de don Alfonso aparecían como muy ligeras y no bastaban, por tanto, para retener a Salvador dentro de las filas de quienes podían llevar el calificativo de hombres de letras.

De aquí que en lugar de Xavier, autor, desde antes, como se ha visto, de varias cosas referidas a Reyes, quien tomara la iniciativa de comentar el libro haya sido Novo; es decir, la exigencia de que así fuera provino de su parte, en contraposición con un Villaurrutia que argumentaba que en "su" revista debía ser él quien se ocupara de los afanes gongorinos de quien era su mayor figura tutelar viviente.

Finalmente las razones de Novo se impusieron, con lo que vino a prevalecer un criterio de cualquier manera más acorde con la naturaleza de la obra, tal como se aprecia en el resultado que se ha transcrito páginas atrás: una original recensión en la que campea el humor desprendido de ese divertimento que, para serlo -y aquí está la cara oculta del aparente juego - se sustenta no únicamente en el ojo avizor del experto en cuestiones tipográficas como requisito previo para embarcarse en la aventura, sino también, y sobre todo, en el conocimiento casi omnisciente de Góngora en primer lugar; en la frecuentación de las fuentes más clásicas de las letras españolas, en el manejo de una bibliografía so- 
bre creadores españoles que incluía toda clase de ediciones, desde las más sencillas hasta las que se hacen acompañar del impresionante aparato crítico erudito: Biblioteca de Autores Españoles de Rivadeneyra, las obras de Menéndez y Pelayo, Morel-Fatio, Américo Castro, etc., lo mismo que revistas especializadas; junto a todo esto se encuentra el resto del inventario de su rico bagaje cultural, en que aparecen igualmente bien conocidas por él las literaturas hispanoamericana, francesa, inglesa y la primicia que aportó entre nosotros de la norteamericana moderna.

Y si de 1927 se da un salto adelante en el tiempo para situar mejor a ese Novo "corrector de pruebas", se apreciará que la revisión de las Cuestiones gongorinas de don Alfonso no es tan simple como parece a primera vista, porque para poder hacerla son necesarios elementos muy precisos y muy propios de los sabios y que, aun cuando han sido enunciados en parte, aprehenderlos desde una perspectiva posterior confiere una condición más afirmada de experto en tales cuestiones a su autor. Vale decir, cuando años después Novo recorre de nueva cuenta todo ese universo en que antes tuvo que internarse, viene a ratificar todo lo anterior.

A raíz de que en enero de 1951 (muy reciente todavía la muerte de Xavier Villaurrutia: 25 de diciembre de 1950), don Alfonso le enviara su poemario Minuta de clara inspiración manducatoria, en su sección "Cartas viejas y nuevas de Salvador Novo", dejó un testimonio que para los fines que aquí se persiguen resulta más que conveniente transcribir en su casi totalidad, para apreciar el sentido de lo antes dicho:

Esta mañana había recibido en la oficina la Minuta de Alfonso Reyes, con una dedicatoria en que me decía que leyó "los preciosos artículos sobre la gula castellana", y que por eso me enviaba su $M i$ nuta. En efecto, la lectura en cama, durante el catarro, de la Historia de la gastronomía de la señora Mestayer de Echagüe, me indujo a revisar muy por encima la poesía castellana en busca de las alusiones gastronómicas que esa señora sentenciaba escasas en esa literatura. Escribí con esa primera búsqueda dos "Ventanas" para Novedades. Pero la notita de Alfonso me estimuló a sistematizar, reanudándola, aquella investigación. De suerte que en ello me ocupé, y muy gratamente, sábado y domingo, aquí, en la terraza en que escribo estas líneas, muy a mano mis clasicotes castellanos que tanto manejé cuando daba clases, y que al releerlos, y hallar en ellos marcas de papel, subrayados y signos hechos en otras épocas, me angustian con la comprobación de que mi memoria no es tan buena como me jacto, pues he olvidado totalmente por qué anoté lo que anoté, 
y aquellos versos o aquella comedia o novela en que perduran las llamadas y marcas.

Lo cual, en cierto modo, es bueno. Así la lectura ofrece el renovado deleite de un descubrimiento, sobre todo cuando se emprende con un objeto fresco y determinado, como ahora el de buscar alusiones a la comida. Empecé, pues, por el venerable tomo 57 de la Rivadeneyra: recorrí a Berceo, y extraje de sus Signos que aparecerán antes del juicio final algún ejemplo. Luego, el largo Poema de Alejandro, que tiene trozos tan bellos, me dio otro, y muchas veces la tentación de transcribir descripciones preciosas. Nada hallé en Sem Tob. Pero en el Tractado de la doctrina empieza a aparecer la gula como pecado, y en el canciller López de Ayala encontré la primera enumeración de golosos castigados que, como un cliché, repiten más tarde, en la misma, idéntica continuidad, todos los poetas que traten de ese pecado: algunos con gracia selectiva, como el Arcipreste cuando increpa a don Amor y mienta a los golosos pecadores bíblicos; otros con menor gracia y mayor extensión, hasta la desorbitada del romance sagrado tardío que ya había yo citado en las primeras Ventanas que consagré a esto.

Agotados los anteriores al siglo XV, era cuestión de entrar, o en los Romances, o en los Cancioneros. Preferí este camino, porque obviamente los poetas de corte serían más tragones o más famélicos que los populares y anónimos. Revisé, pues, el Baena, el Foulché Delbosc, la antología de don Marcelino, con buena ceza. Y me detuve largamente en el Cristóbal de Castillejo que cuenta en las ediciones de La Lectura con tres tomos bien anotados. Ahí encontré la primera y muy buena descripción del "gorrón" que cae a la hora de la comida, y sus penalidades cuando ya comieron en esa casa; y la cuenta y razón de sus interesantes minutas de Viena.

Luego empiezan ya, como usted recuerda, los bucólicos artificiosos, y éstos, cuando menos en la poesía, comen poco. Prefieren penar de amor en las peñas, y se contentan con una dieta láctea que extraen de sus vacas y sus ovejas. Es preciso llegar a pleno siglo de oro para hallar comprobada una influencia italiana en las costumbres que el gruñón, ascético a su peculiar modo, traductor fervoroso de Séneca y desmañado de Anacreonte, enemigo insolente de Góngora, Quevedo, en fin, denostaría en su hermosa Epistola-censoria al conde-duque de Olivares, por lo que atañe a la degeneración epicúrea de una mesa española que había dejado de contentarse con "pimientos y ajos" - que antes bastaron a señores y esclavos- para caer en el exotismo de sazonarse con "pimienta arrugada" y "clavo extranjero". Las perseguidas, soñadas islas de la especiería, empezaban a refinar los paladares aun en España.

¡Qué solaz, qué descanso, qué complicidad releer a un Baltazar del Alcázar que sí se abandona gustoso a los placeres de la mesa! 
¡Cómo nos hace saborear, uno a uno, "la morcilla, gran señora digna de veneración", y todos los demás platillos de una cena que adormece su charola! Pero más que con esa cena siento una afinidad por esa otra joyita suya, la Vida del autor en la vejez, en que refiere con una gran elegancia cómo - y con qué sobria dieta- pasa sus días.

No sé hasta dónde podría llevarme, si la continuara, esta crestomatía gastronómica. Desde luego, componer con ella Ventanas para un diario no puede ser muy del gusto de sus lectores, y he de concluirla ya, porque además en tres cuartillas no se puede citar mucho ${ }^{20}$.

La cita precedente hecha in extenso ha sido con objeto de ilustrar el manejo formidable que hacía Novo de toda esa bibliografía en la que se halla sustentada, además de en su ojo de lince para la errata, la nota sobre Cuestiones gongorinas de don Alfonso y que, por sus características, sólo halla equivalente entre nosotros en aquella otra del mismo Novo publicada en Letras de Mé$x_{i c o}{ }^{21}$ en donde se aplica a registrar "Mexicanismos de El Pensador Mexicano", entresacados de Vida y hechos del famoso Caballero D. Catrín de la Fachenda, según la edición de D. Alejandro Valdés de 1832.

Hay que recordar igualmente su dominio de la métrica, del ritmo y de la rima cuando componía poesía en formas tradicionales, así fuera meramente de circunstancias, para preguntarse si no es ello buena prueba de hasta dónde llegó en su penetración de los cauces americano y español del fenómeno poético en nuestra lengua y, también, de dónde, si no es de un conocimiento exhaustivo de las fuentes mismas - y no de fechas recientes- provenía su discurso de ingreso en la Academia Mexicana de la Lengua, en donde examina la presencia de los personajes canoros y de pluma, esto es, Las aves en la poesía castellana ${ }^{22}$.

Sobre esta última referencia hay que hacer el señalamiento no sólo obligado sino de manera muy destacada, de que una vez que leyó la disertación mediante la cual accedió a ocupar su sitial académico, nada menos que el mismísimo autor de las Cuestiones gon-

${ }^{20} \mathrm{~S}$. Novo, La vida en México en el periodo presidencial de Miguel Alemán, pp. 563-565.

${ }^{21}$ S. Novo, "Mexicanismos de El Pensador Mexicano", Letras de México, 1939, núm. 10, p. 2.

${ }^{22}$ Salvador Novo, Las aves en la poesía castellana, discurso leído ante la Academia Mexicana, correspondiente de la Española, el día 8 de septiembre de 1952, Gráfica Panamericana, México, 1953. 
gorinas le envió una cuarteta laudatoria que merece insertarse aquí. La poética, breve comunicación lleva el título de: $A S A L V A D O R$ NOVO por su discurso ornitológico en la Academia:

No, ni la "calandria triguera"

de la Egipciaca María

trinaba de mejor manera.

¡Venga esa mano: ésta es la mía!

17 de febrero de $1954^{23}$

Y por lo que respecta a los resultados conseguidos por la nota dedicada al libro gongorino de don Alfonso, quizá su mejor logro sea el hecho de que en el aspecto literario, por una parte, la relación Reyes-Novo se hizo tanto o más estrecha que la que hubo entre quienes establecieron el binomio original, es decir, ReyesVillaurrutia, al punto de que en algún momento cuando habló de ciertos envíos bibliográficos recibidos, Novo menciona que:

De las “personas grandes" hay aquí unos libros: las Viñetas ilustres de Agustín Loera y Chávez y los Ancorajes de Alfonso Reyes, con quien tengo establecido un frecuente intercambio secreto de ediciones restringidas y de cartas breves ${ }^{24}$.

En este mismo sentido de la relación literaria, algunos de los fragmentos transcritos antes son buena muestra de ello, v.gr., la crestomatía gastronómica elogiada por don Alfonso y continuada a partir del envío de Minuta; la breve cuarteta poética; o lo que a continuación se recoge y cuya elocuencia torna ociosa toda exégesis, salvo llamar la atención sobre el poema de Reyes que ahí se incluye y que no está coleccionado en libro:

He puesto en venta unos cuantos ejemplares de mi monólogo. En la Librería de Cristal hicieron un escaparate con algunos de mis libros y un retrato. Quiero darles las gracias. Y también a Alfonso Reyes, que al acusarme recibo del monólogo, me puso esta carta: "Querido Salvador: Gracias por su atención para Manuel Bandeira. Gracias por El Joven II, que me ha hecho meditar mucho. Es algo que se sale de la literatura y entra como cuchillo en el corazón. El hombre reducido a su mínima expresión. Una verdadera requisitoria contra la especie, en que nos sentimos todos aludidos.

23 Alfonso Reyes, Constancia poética, en AROC, t. 10, pp. 306-307.

${ }^{24} \mathrm{~S}$. Novo, La vida en México en el periodo presidencial de Meguel Alemán, pp. 656-657. 
En 1931 también yo me enfrenté con el joven que llevo adentro y me sentí asqueado, a la Sartre. Entonces escribí el poema que aquí le copio y que he dejado inédito, porque me di cuenta de que nadie lo entendía y porque no me da la gana de ser más explícito:

\section{AYER Y HOY}

Aquel mancebo de quien soy esclavo vino hasta mí con sol en los cabellos, me asió con fuerza, me empujó en la barca, se dio a bogar y me dejó en la orilla.

Los brazos implorantes contra el cielo, quise gritar, de llanto sacudido,

-Señor ¿Por qué abandonas a tu esclavo?

Él flotaba en la gracia de la vida. Y lo miré correr de espalda al tiempo.

Un abrazo cordiai

Alfonso Reyes ${ }^{25}$

Cuando en 1945 recogió Reyes en dos volúmenes "sus agotadas Simpatías y diferencias, más El cazador" , Novo anotó unas opiniones que, no obstante su apretada redacción, pues se hallan contenidas en el cuerpo de una colaboración periodística más larga, dicen mucho con respecto al trato que tenía de muy antiguo con la obra alfonsina:

Releo con deleite estos ágiles, periodísticos (en el buen sentido, que suele o ha solido haberlo) ensayos que hace muchos años nos hicieron conocer y querer a un Alfonso Reyes desterrado en España, atareado en vivir de la pluma entre extraños que vivían también de eso. Claro está que admirábamos mucho sus Cuestiones estéticas; tanto como a él mismo; pero nos gustaban más sus Simpatías y diferencias, tan actuales, que siguen siéndolo ahora que el cine, que aborda silencioso y en pañales, sigue en pañales, pero ya habla; que la guerra que acababa de pasar entonces, también ahora acaba de pasar; que perdura la preocupación norteamericana por una solidaridad, una amistad leal sudamericana o de habla española, que aho-

25 "Cartas viejas y nuevas de Salvador Novo", Mañana, 21 de julio de 1951, 14-15. 
ra como entonces, como cuando resolvieron estudiar español, se anda por los cerros de Úbeda para lograr sus fines.

Es impresionante y curioso volver a leer la Carta a dos amigos en que Alfonso encarga a Genaro Estrada y a Enrique Díez-Canedo -por si muere en México o en España- de la publicación póstuma y ordenada de sus Obras completas: el testamento literario a cuyos ejecutores tentativos - muertos ambos en México- sobrevive el testador ${ }^{26}$.

Con posterioridad a esta breve alusión a parte de la obra de don Alfonso, Novo se volvió a ocupar de ella a propósito de la publicación de ocho títulos que aparecieron de golpe en 1948; de esto habló en una nota cobijada con el título de "El pan con la pluma":

... Cinco corresponden a las series del Archivo: E.-testimonios, 2: La Conferencia Colombo-Peruana para el arreglo del incidente de Leticia; 3, Momentos de España, Memorias políticas; 4, Crónica de Francia; D. Instrumentos, 2: La inmigración en Francia; y B. Astillas, 1, Burlas literarias (1919-1922). Los otros tres: Entre libros, De un autor censurado en el Quijote (Antonio de Torquemada) y Cortesía (1909-1947) vuelven a "limpiar la mesa" del escritor que en 1926 ya reconocía que "para ganar el pan con la pluma hay que escribir mucho"'27.

En ambos casos, Reyes expresó su agradecimiento por la generosidad y por el conocimiento de su obra que rezumaban tales notas de quien llegó a ser su colega en la Academia de la Lengua.

Aun cuando se ha ido haciendo evidente - entiendo- a lo largo de este trabajo, no debe pasarse por alto una cuestión tan importante como resulta ser el hecho de que con el correr del tiempo la relación Reyes-Novo, en el aspecto humano, en su expresión más vital, o sea, en el sentido de encontrarse identificados como interlocutores ideales, vino a hacerse más estrecha, más constante, porque el eslabón del humor, la ligadura que se establecía por medio del espíritu lúdico que insuflaba a uno y otro, los acercó plena, definitivamente.

Así pues, una vez abiertas las puertas de esa comunicación sustentada en un buen talante que tan escasamente se halla en

${ }^{26}$ S. Novo, La vida en México en el periodo presidencial de Manuel Avila Camacho, ed. José Emilio Pacheco, Empresas Editoriales, México, 1965, p. 619.

${ }^{27}$ S. Novo, "El pan con la pluma", Novedades, 1 de julio de 1948; recopilado en Páginas sobre Alfonso Reyes, Universidad de Nuevo León, Monterrey, 1955, t. 2, pp. 44-46. 
nuestros escritores aún hoy, sobre todo así de rotundo y vivaz, las manifestaciones de ingenio, al igual que las doctamente eruditas, menudearon entre ellos, ya por teléfono, ya intercambiándose mensajes en mitad de solemnes sesiones de la vida cultural. A este último respecto, véase este significativo ejemplo que quedó atesorado en una de las colaboraciones que Novo entregaba a las publicaciones periódicas:

Por la tarde asistí a la copiosa junta del Comité de Chopin, que preside el Licenciado Portes Gil, pero del que forman parte las más surtidas y heterogéneas personas eminentes. Mientras el licenciado Romandía Ferreira leía un informe, y atribuía comisiones y trabajos a los distintos miembros, y se les ocurrían miles de formas en que honrar a Chopin, Alfonso Reyes y yo, que estábamos sentados muy cerca, nos distraíamos con improvisar versos. Por ejemplo, hubo un momento en que leyeron la proposición de que en todos los pueblos de la República se buscaran pianistas chopinianos que llevar a un concurso, y entonces le dije a Alfonso:

"Pero una duda me atribula:

¿pianistas de Chalchicomula?"

Y Alfonso me respondió:

"Pues de Sonora a Yucatán tocan música de Chopin"'28

Además de las salutaciones como la transcrita por el discurso académico de Novo, hubo otras como la siguiente, que con el encabezado de Recado a Salvador Novo, le enviara don Alfonso:
"Amistad intermitente" ha llamado Salvador a la de un viejo escritor que se aísla de la gente. Sea Salvador clemente $y$ considere el ingrato que la vida es breve rato para la pluma glotona, y a cambio de la persona, guarde consigo el retrato.

3 de marzo de $1950^{29}$

${ }^{28}$ S. Novo, La vida en México durante el periodo presidencial de Miguel Alemán, p. 306 .

29 Constancia poética, p. 297. 
Hubo, además, la circunstancia de que en 1934 Novo formara parte de la Delegación Mexicana que asistió a una conferencia internacional efectuada en Montevideo, lo que posibilitó el hecho de que, en ruta al Uruguay, pasaran los delegados por Río de Janeiro donde a la sazón don Alfonso estaba al frente de nuestra representación diplomática. Como lo refiere en su libro Continente vacio, en el que recoge sus impresiones de ese viaje, Reyes fue un magnífico anfitrión del grupo y esa ocasión, puesto que se dio fuera de México, quiero decir, esa ocasión de tratar a don Alfonso, fue, claro, otro de los elementos que ahondaron más la amistad entre ambos.

Paradójicamente, el estrechamiento mayor de la relación no ocurrió en el caso de Villaurrutia, especialmente en la época en que, ya avecindado Reyes en México, pudo darse mayormente la convivencia, es decir, más allá de la usual relación traducida en encuentros en conferencias, exposiciones, conciertos, reuniones de comités, etc. Ello fue debido a que (como bien lo ha recordado Octavio Paz en el libro donde aborda a Xavier Villaurrutia en persona y en obra), el autor de esos Nocturnos tan básicos en nuestra poesía y que tanto dicen, justamente, de su personalidad más recóndita, era poseedor de un carácter retraído y menos inscrito en la joie de vivre, lo que por fuerza hacía restringir su contacto con don Alfonso a una frecuentación que si bien estaba marcada por el sello de una familiaridad indiscutible, prefería situarse dentro del campo de una seriedad, de un tono siempre formal - como queda apuntado antes también - y era a partir de ello únicamente que establecía el diálogo con un Reyes más situado en una línea vitalista.

El trato entre don Alfonso y Novo quedaría interrumpido por la muerte del primero el 27 de diciembre de 1959. Sin embargo, Novo proseguiría invocando su presencia, y para esto acudió también a la vía del humor cuando unos años después, en 1963, al ser inhumados en la Rotonda de los Hombres Ilustres los restos de Ramón López Velarde, aprovechó la ocasión para escribir uno de sus célebres Diálogos, esta vez de varios personajes, pues hace intervenir en éste a todos los prohombres - y a la única mujer incluida hasta ese momento: Ángela Peralta - que se hallan enterrados en esa parcela que asegura la inmortalidad nacional.

Llena de la gracia, del humorismo que extrae de ese venerable Panteón patricio e intelectual, la breve pieza no deja de tener su conexión con toda la mexicana usanza de las calaveras literarias y es, también, una muestra magnífica de la capacidad dra- 
mática de Novo. Aun cuando las relaciones Reyes-López Velarde, por las diversas causas ya sabidas, no fueron realmente amistosas, es curioso cómo Novo, en este caso, los pone en contacto.

Dada su extensión, hay que limitarse a dar aquí apenas un vislumbre de la obra, en donde el Alfonso Reyes de ultratumba que presenta Novo conserva muchas de las características que en vida lo definieron:

\section{ESCENA I}

(Deslumhrado por el vivo sol de la ceremonia, Ramón no alcanza a distinguir, en la sombra, al Hombre Ilustre cuya voz es lo primero que escucha:)

Voz

¡Ay, ay, Ramón! ¡Por fin nos acompañas!

Llégate a mí. Te mostraré el camino

deste oscuro lugar de alto destino

que pueblan héroes, genios, telarañas...

¡Pudiera recibirte con champañas,

néctar, guirnaldas -o siquiera vino!

Voy a medio soneto. Desatino.

Es una - ¿lo recuerdas? - de mis mañas.

Nuestros colegas me han comisionado

para atenderte.

\section{Ramón}

Gracias. Pero no recuerdo, señor, que nos tuteáramos. Yo, verá usted...

\section{Voz}

¡Muchacho! Puedo llamarte así, a tus treinta y tres años, desde mis setenta cumplidos; aunque me hubieras alcanzado si ... Pero acá todos rompemos el turrón. Más vale así, hemos de convivir -es un decir - por toda una eternidad... iQué gusto me da verte! A tu fallecimiento, yo me hallaba en Madrid, creo, o en París. . . No pude conocerte en persona, pero... Soy Alfonso - Alfonso Reyes!

\section{Ramón}

Honradísimo. Yo le admiraba mucho, señor...

Alfonso

Llámame Alfonso. Llevo aquí cerca de cuatro años. Conozco a todos los inquilinos de este... condominio. Ya te los iré presentando. Pero háblame de ti: de la ceremonia de tu mudanza entre nosotros. ¿Brillante? ¿Te satisfizo? 


\section{Ramón}

Completamente inesperada. Se la agradezco mucho al Presidente Obregón.

\section{Alfonso}

¿Obregón? ¡Fue López Mateos! ¡El mismo que me enterró a mí!

\section{Ramón}

Perdón. Confundo la cronología. Cuarenta y dos años de residencia y olvido en el Francés... Fue una sorpresa, casi una zozobra verme exhumado y conducido a una ceremonia tan ... emotiva.

\section{Alfonso}

Debe haberlo sido. Mi sepelio fue también muy lucido. Pero a mí me trajeron aquí directamente, y en seguida. Los tiempos han cambiado, Ramón. Ahora somos ilustres desde en vida. El trámite es simple y expedito; antes de aquí canonizarnos, nos canonjizan en El Colegio Nacional. Ser miembro suyo es como una graduación de ilustrismo, como advenir a un título o conseguirse un pasaporte. Ya de ahí, directamente acá, simplemente como un refrendo o una jubilación. Pero sigue. Perdón por la interrupción. Hablabas de tu ceremonia $^{30}$.

Sea suficiente con estas páginas para mostrar algunos de los puntos por medio de los cuales quedó establecida una amistad entre escritores, una relación que, obviamente, tuvo otras abundantes manifestaciones, pero cuya mera enumeración, como se ha hecho aquí, rebasaría los límites de esta publicación.

Quédese entonces para otra vez el hablar de cómo detrás de esta relación anda por ahí también como un oculto, silencioso motor, la presencia de Pedro Henríquez Ureña que tan determinante fue lo mismo para Reyes que para Novo; además, se trata por ahora, en primera y última instancia, de celebrar el centenario de ese hombre que tanto me pesa no haber conocido, el Alfonso Reyes cuyas "Burlas Veras'" fue lo primero suyo que leí cuando las publicaba cada semana en las páginas de Revista de Revistas, y esto allá en mis días de escuela secundaria de mi natal y provinciana Córdoba, antes de llegar al Distrito Federal, donde sí tuve el privilegio de tratar, estudiar y colaborar con quien para mí es, indiscutiblemente, el Maestro Novo.

\section{Miguel Capistrán}

${ }^{30}$ Diálogo de ilustres en la Rotonda, en In Iticitezcatl o El espejo encantado, Universidad Veracruzana, Xalapa, 1966, pp. 161-183. 